\title{
Interprofissionalismo nas Residências Multiprofissionais em Saúde: análise na região nordeste do Brasil
}

\author{
Maria da Conceição Carneiro Pessoa de Santana, Rosana Aparecida Salvador Rossit
}

\begin{abstract}
Resumo
O interprofissionalismo abrange a comunicação entre as diferentes profissões, bem como a integração do cuidado especializado com cuidado holístico, opondo-se ao reducionismo e à fragmentação da visão de uma profissão isolada (Freeth, 2007). A Educação Interprofissional e as práticas colaborativas que acontecem dentro de um contexto de aprendizagens compartilhadas são temas que vêm sendo amplamente discutidos em nível global (Frenk et al., 2010), enfatizando a importância da reformulação do modelo de formação profissional na saúde (Peduzzi, 2013). Dentre as propostas que favorecem o treinamento conjunto, no âmbito das aprendizagens compartilhadas, a Residência Multiprofissional é considerada um tema relevante de estudo no que se refere aos novos padrões de formação, por ser uma ação estratégica para transformar a organização dos serviços, o processo de formação, as práticas de saúde e as práticas pedagógicas (Brasil, 2006). Devido à escassez de estudos que correlacionaram temáticas como interprofissionalismo e Residência Multiprofissional em Saúde (RMS), especialmente quanto à consideração dos princípios desse estilo de educação e à percepção dos integrantes dos programas, surgiu o interesse de investigar o interprofissionalismo, por entender que os Programas de Residência Multiprofissional em Saúde da Região Nordeste do Brasil são ofertados em contextos desafiadores, com necessidade de superação de problemas de saúde pública, mediante recursos considerados limitados. Acredita-se que a formação pode qualificar o profissional para uma assistência de efetiva resolubilidade e transformadora da realidade local. O estudo teve como objetivos analisar o interprofissionalismo nas Residências Multiprofissionais em Saúde da Região Nordeste do Brasil; mapear os princípios da Educação Interprofissional contido nos Projetos Pedagógicos dos Programas de Residência Multiprofissional em Saúde do Nordeste do Brasil; analisar a percepção dos integrantes desses Programas sobre a aprendizagem compartilhada, a formação para trabalho em equipe e o desenvolvimento de competências para as práticas colaborativas; e identificar potencialidades, fragilidades e sugestões para o aprimoramento do interprofissionalismo nas Residências Multiprofissionais em Saúde com vistas à integralidade do cuidado. A pesquisa de cunho exploratório, transversal, descritivo- analítica, com abordagem quali-quanti foi desenvolvida no cenário dos Programas de RMS em nove estados da Região Nordeste do Brasil. Inicialmente, realizou-se a análise documental de Projetos Pedagógicos (PP) dos Programas, caracterizados como fonte primária de dados, a partir de um protocolo de termos rastreadores construído para esta finalidade. Do universo de 42 Programas de RMS, 13 PP (30,9\%) foram localizados e/ou disponibilizados pelos coordenadores e analisados. Posteriormente, foi aplicada uma escala atitudinal tipo Likert, com espaço aberto para registro de contribuições espontâneas. Os dados foram coletados junto a 237 residentes matriculados no segundo ano da RMS e 129 docentes integrantes do Núcleo Docente Assistencial Estruturante dos 42 Programas, sendo: 66 preceptores, 44 tutores e 19 coordenadores. Uma planilha eletrônica MS-Excel, em sua versão do MS-Office 2010, foi utilizada para a organização dos dados e o pacote estatístico IBM SPSS (Statistical Package for Social Sciences) em sua versão 23.0, para a análise dos dados. Os recursos estatísticos utilizados foram Teste de Correlação Linear (r) e gráficos de barras. Da transcrição das respostas da questão aberta, analisaram-se as contribuições e sugestões com o referencial da análise temática. Realizou-se um diálogo entre os dados quali-quanti, vislumbrando consonâncias ou dissonâncias
\end{abstract}


ISSN 2179-6750

para aprofundamento e reflexões do objeto em estudo. A pesquisa foi aprovada pelo CEP-UNIFESP, Parecer No 1.094.027 de 03/06/2015. A análise dos PP apontou que os princípios do interprofissionalismo estão parcialmente contemplados nos documentos e evidenciou-se um cenário heterogêneo em relação a esses princípios. Apesar da não identificação de alguns termos rastreadores nos PP, constatou-se que os Programas de RMS do Nordeste do Brasil se constituem em espaço potente para o interprofissionalismo. Em relação à escala atitudinal, constatou-se predomínio das respostas no intervalo das médias entre três e quatro, o que indicou a concordância em relação aos aspectos investigados e o preparo dos residentes e docentes. A percepção dos participantes sobre o preparo para o interprofissionalismo nas RMS do Nordeste do Brasil foi classificada em zona de conforto e indicação de providências de manutenção. A análise temática apontou que, para que o interprofissionalismo ocorra no processo de formação e para alcançar a integralidade do cuidado, demanda-se maior efetividade e harmonia na integração entre residentes, preceptores e tutores preconizadas no preparo intencional dos profissionais de saúde, na perspectiva do interprofissionalismo. Conclui-se que a análise dos PP de programas de RMS do Nordeste brasileiro possibilitou um aprofundamento no discurso político-pedagógico desta proposta formativa. A metodologia utilizada no estudo favoreceu a identificação de iniciativas de interprofissionalidade nos cenários das RMS, sendo esses considerados parcialmente favoráveis aos princípios da EIP. Ressalta-se que, nesta pesquisa, foi possível conhecer o currículo planejado e disponível nos PP. Sugere-se a realização de outras investigações que utilizem diferentes metodologias de pesquisa que permita explorar outros tipos de currículo, como o oculto e o currículo real. Existem desafios relacionados aos processos de implantação e implementação do interprofissionalismo nos programas estudados. Todavia, as percepções dos participantes foram positivas, com classificação de conforto e indicação de providência de manutenção, sobre aprendizagem compartilhada, formação para trabalho em equipe e desenvolvimento de competências para práticas colaborativas. A análise temática apontou que, para que o interprofissionalismo ocorra no processo de formação proposto pelos Programas de RMS, é necessário que, intencionalmente, sejam organizados ambientes de compartilhamento de aprendizagens proporcionada pelo respeito, diálogo aberto, definição de papéis e responsabilidades e, em especial, o preparo dos que estão envolvidos para a atenção à saúde centrada na pessoa sob cuidado para alcançar a integralidade do cuidado. Além da relevância científica, destaca-se a relevância social da pesquisa, especialmente no âmbito da gestão, com reais possibilidades dos resultados serem utilizados como respaldo teórico para embasar reflexões relacionadas ao atual cenário da Região Nordeste do Brasil. Este estudo revelou o interprofissionalismo como um possível promotor do desenvolvimento de competências para a prática colaborativa nos PRMS. Dessa forma, no contexto das RMS do Nordeste do Brasil, a colaboração interprofissional ocorrerá como um movimento efetivo que deslocará o formato multiprofissional para o interprofissional, assim como a condição de trabalho estruturado em torno da simples divisão do trabalho para a colaboração (Agreli et al., 2016), que contempla o planejamento de ações que serão executadas para alcançar objetivos com vantagens tanto para os profissionais quanto para os usuários dos serviços de saúde

Descritores: Relações Interprofissionais, Educação de Pós-Graduação, Pessoal de Saúde, Integralidade em Saúde 